\title{
Mini-open PLIF for Moderate to High Grade Spondylolisthesis: Technique to Achieve Spontaneous Reduction
}

\author{
Se Ho Jeong ${ }^{1}$, Hyeun Sung $\mathrm{Kim}^{2}$, Seok Won Kim ${ }^{1}$ \\ ${ }^{l}$ Department of Neurosurgery, Chosun University College of Medicine, Gwangju, \\ ${ }^{2}$ Department of Neurosurgery, Nanoori Hospital, Suwon, Korea
}

\begin{abstract}
Objective: The purpose of this study was to evaluate the surgical technique and outcome of mini-open posterior lumbar interbody fusion (PLIF) under circumferential releasing technique.

Methods: Fourty patients who underwent mini-open PLIF using the percutaneous screw fixation system for Meyerding Grade II spondylolisthesis or more were retrospectively studied. After complete circumferential release, the slipped vertebrae would tend to obtain spontaneous reduction, and with compressive force by percutaneous screw fixation, additional reduction could be achieved. The radiological measurements including slippage reduction, disc height, restoration of lumbar lordotic angle and focal segmental angle were analyzed. The clinical outcome was assessed using the visual analog scale (VAS) and low back outcome score (LBOS), and procedure related complications were also analyzed.

Results: Slippage percentage was improved from $38.0 \pm 12.6 \%$ to $9.3 \pm 7.8 \%$ and lumbar lordotic angle was changed from $43.0 \pm 13.8^{\circ}$ to $48.2 \pm 10.3^{\circ}$. Focal segmental angle improved from $10.1 \pm 8.5^{\circ}$ to $15.9 \pm 6.0^{\circ}$. The mean LBOS and mean pain score were also improved significantly. Complications included one case of medial penetration of pedicle border and two cases of transient radiculopathy. However, there were no signs of neurological aggravation or fusion failure during the follow-up period. Conclusion: Mini-open PLIF using the percutaneous screw fixation following complete circumferential release can be safe and effective treatment for even moderate to severe grade spondylolisthesis.
\end{abstract}

Key Words: Spondylolisthesis · Fusion · Reduction

\section{INTRODUCTION}

The term spondylolisthesis describes a pathologic slippage of one vertebra against another. It is one of the spinal diseases requiring fusion surgery. Posterior fusion techniques including posterolateral fusion, posterior lumbar interbody fusion (PLIF), transforaminal lumbar interbody fusion (TLIF) and circumferential fusion have been performed to treat spondylolisthesis ${ }^{7}$. Bone fusion and screw fixation have been associated with a high fusion rate, especially in the treatment of low grade spondylolisthesis in which the segment of the spinal column to be

- Received: July 3, 2015 • Revised: September 11, 2015

- Accepted: November 9, 2015

Corresponding Author: Seok Won Kim, MD, PhD

Department of Neurosurgery, Chosun University College of Medicine,

365 Pilmun-daero, Dong-gu, Gwangju 61453, Korea

Tel: +82-62-220-3126, Fax: +82-62-227-4575

E-mail: ns64902@hanmail.net/chosunns@chosun.ac.kr

@This is an Open Access article distributed under the terms of the Creative

Commons Attribution Non-Commercial License (http://creativecommons.org/

licenses/by-nc/3.0/) which permits unrestricted non-commercial use, distribution,

and reproduction in any medium, provided the original work is properly cited. fused is under a more compressive load. However, the high shear stress at the lumbar or lumbosacral junction in moderate to high grade spondylolisthesis alters this bio-mechanical advantage. Moreover, forceful slip reduction was reported to have an high rate of neural injury caused by distraction of nerve $\operatorname{roots}^{2,13-15)}$. The correction degree of sagittal translation is still controversial focus on method and degree for symptomatic spondylolisthesis. So far, it has not been clear whether potential benefit or lack thereof is due to the translational or the angular reduction, and it is difficult to form a clear guideline for spondylolisthesis. Moreover, the use of minimally invasive mini-open PLIF using the percutaneous screw fixation system for moderate to severe spondylolisthesis has not been previously described. The current study describes the surgical technique and feasibility of the mini-open PLIF with percutaneous screw fixation for moderate to high grade spondylolisthesis to achieve spontaneous slip reduction minimizing neural injury.

\section{MATERIALS AND METHODS}

Between January 2007 and December 2010, 40 consecutive 
patients who underwent mini-open PLIF for Grade II spondylolisthesis or more were included in this study. The inclusion criteria were: (1) no previous surgery at the level of spondylolisthesis, (2) followed up for at least 12 months, and (3) no severe osteoporosis (the lowest T-score on dual energy X-ray absorptiometry bone mineral density $>-3.0)$. The patients' age ranged between 29 and 68 years (average 59.4) and mean follow-up period was $24.1 \pm 13.5$ months. The preoperative diagnosis was 22 cases of degenerative type and 18 cases of isthmic type, comprising 32 cases with Meyerding Grade II, 5 cases with Meyerding Grade III and three cases with Meyerding Grade IV. Spondylolisthesis was present at the L3-4 level in three patients, at the L4-5 level in 24 patients and at the L5-S1 level in 13 patients.

\section{Surgical Technique}

All patients underwent mini-open PLIF in the prone position. Following a midline skin incision, an expandable tubular retractor of appropriate length (X-tube, Medtronic Sofamor Danek, Memphis TN., USA) was inserted at each level. Decompressive surgery consisted of transfacet laminectomy and foraminotomy bilaterally. Complete removal of the scar tissue around the pars interarticularis led to the sufficient liberation of the nerve root under the slipped pedicle, achieving posterior release as well. The disc inferior to the slipped vertebrae was thoroughly resected, lateral to both pedicles, in which course, the disc space was gradually distracted and released with sequential disc shavers, removing of the anterior annulus as much as possible that was even in conjunction with anterior longitudinal ligament (ALL) to accomplish exhaustive anterior release, followed by insertion of cages bilaterally. During the maneuver, due to circumferential release, it could be found that the slipped vertebrae tended to obtain partial spontaneous reduction. Secondly, percutaneous pedicle screws with a vertical axis and detachable extender (Apollon system ${ }^{\circledR}$, Solco medical, South Korea) were inserted without additional skin incision. After dissection of the subdermal plane, the percutaneous screws were inserted following retraction of the skin. Furthermore, with the compressing the screws into each other to create a lumbar lordosis, additional reduction could be achieved without any application of compulsive force. Imaging and clinical findings including involved level, slip percentage, lumbar lordotic angle, focal segmental angle, clinical outcomes, and complications were analyzed. Clinical outcomes were measured using a self assessment 10-point visual analog scale (VAS) and low back outcome score (LBOS) normalized to 75 (Table 1).

\section{Radiological Measurement}

The slippage was measured from standing lateral radiographs and calculated as the quotient of sagittal displacement expressed in percent. Lumbar lordotic angle was defined by Cobb's method, using the intersection of lines at the level of the superior plateau of L1 and the inferior plateau of L5. Focal segmental angle was defined as the focal angle of superior line of spondylolisthetic level and inferior line of adjacent lower level.

\section{Statistical Analysis}

All data were saved to an Excel spreadsheet for analysis. Mean values and standard deviations were calculated. Comparisons between different time points were made using Wilcoxon signed rank test. $\mathrm{p}$-values $<0.05$ were considered as statistically significant.

\section{RESULTS}

All patients were followed for at least 12 months and the mean follow-up period was 24.1 months. At a minimum of 12 months follow-up, all cases appeared to have solid fusions as judged by the presence of a trabecular bony bridge or less than $5^{\circ}$ on dynamic flexion and extension views.

\section{Degree of Slippage Reduction}

Preoperative slippage averaged $38.0 \pm 12.6 \%$. At the latest follow-up, mean slippage improved significantly to $9.3 \pm 7.8 \%$ $(\mathrm{p}<0.001)$ (Fig. 1).

\section{Degree of Lumbar Lordotic Angle}

Lumbar lordosis, measured from the upper endplate of L1 to the inferior endplate of $\mathrm{L} 5$, was $43.0 \pm 13.8^{\circ}$ before surgery.

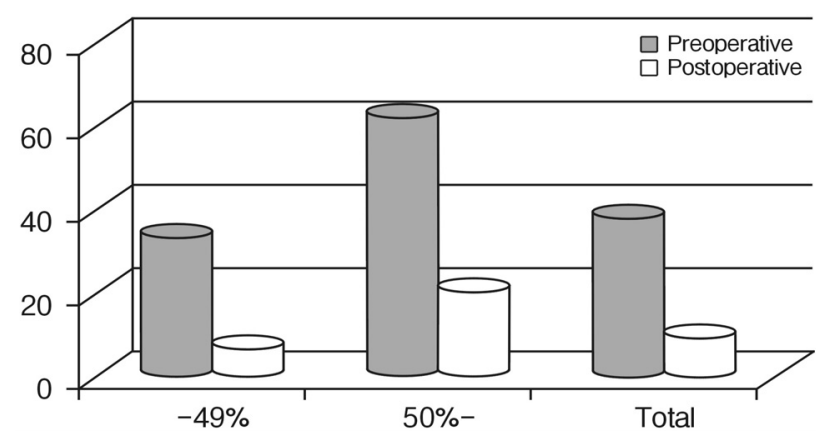

Fig. 1. Degree of slippage reduction. 
Table 1. The low back outcome scale of Greenough and Fraser

\begin{tabular}{|c|c|c|c|c|c|}
\hline Parameter & Finding & Points & Parameter & Finding & Points \\
\hline Current pain & $\begin{array}{l}7 \text { to } 10 \mathrm{~cm} \text { VAS } \\
5 \text { to } 6 \mathrm{~cm} \text { VAS } \\
3 \text { to } 4 \mathrm{~cm} \text { VAS } \\
0 \text { to } 2 \mathrm{~cm} \text { VAS }\end{array}$ & $\begin{array}{l}0 \\
3 \\
6 \\
9\end{array}$ & Sex life & $\begin{array}{l}\text { Severely affected impossible } \\
\text { Moderately affected difficult } \\
\text { Mildly affected } \\
\text { Unaffected }\end{array}$ & $\begin{array}{l}0 \\
2 \\
4 \\
6\end{array}$ \\
\hline Employment & $\begin{array}{l}\text { Unemployed because of back pain } \\
\text { Part time } \\
\text { Full time lighter } \\
\text { Full time original }\end{array}$ & $\begin{array}{l}0 \\
3 \\
6 \\
9\end{array}$ & Sleeping & $\begin{array}{l}\text { Severely affected impossible } \\
\text { Moderately affected difficult } \\
\text { Mildly affected } \\
\text { Unaffected }\end{array}$ & $\begin{array}{l}0 \\
1 \\
2 \\
3\end{array}$ \\
\hline Domestic chores odd jobs & $\begin{array}{l}\text { None } \\
\text { A few but not many } \\
\text { Most or all but more slowly } \\
\text { normally }\end{array}$ & $\begin{array}{l}0 \\
3 \\
6 \\
9\end{array}$ & Walking & $\begin{array}{l}\text { Severely affected impossible } \\
\text { Moderately affected difficult } \\
\text { Mildly affected } \\
\text { unaffected }\end{array}$ & $\begin{array}{l}0 \\
1 \\
2 \\
3\end{array}$ \\
\hline Sport or active social activitis & $\begin{array}{l}\text { None } \\
\text { Some but much less than before } \\
\text { Back to previous level }\end{array}$ & $\begin{array}{l}0 \\
3 \\
9\end{array}$ & Sitting & $\begin{array}{l}\text { Severely affected impossible } \\
\text { Moderately affected difficult } \\
\text { Mildly affected }\end{array}$ & $\begin{array}{l}0 \\
1 \\
2\end{array}$ \\
\hline \multirow[t]{2}{*}{ Resting } & Resting more than half the day & 0 & & unaffected & 3 \\
\hline & $\begin{array}{l}\text { Little rest needed occasional } \\
\text { No need rest }\end{array}$ & $\begin{array}{l}4 \\
6\end{array}$ & Travelling & $\begin{array}{l}\text { Severely affected impossible } \\
\text { Moderately affected difficult }\end{array}$ & $\begin{array}{l}0 \\
1\end{array}$ \\
\hline \multirow[t]{2}{*}{ Treatment or Consultation } & $\begin{array}{l}\text { More than once per month } \\
\text { About once per month }\end{array}$ & $\begin{array}{l}0 \\
2\end{array}$ & & $\begin{array}{l}\text { Mildly affected } \\
\text { unaffected }\end{array}$ & $\begin{array}{l}2 \\
3\end{array}$ \\
\hline & $\begin{array}{l}\text { Rarely } \\
\text { Never }\end{array}$ & $\begin{array}{l}4 \\
6\end{array}$ & Dressing & Severely affected impossible & 0 \\
\hline \multirow[t]{2}{*}{ Analgesia } & $\begin{array}{l}\text { Several times each day } \\
\text { Almost every day } \\
\text { Occasionally }\end{array}$ & $\begin{array}{l}0 \\
2 \\
4\end{array}$ & & $\begin{array}{l}\text { Moderately affected difficult } \\
\text { Mildly affected } \\
\text { unaffected }\end{array}$ & $\begin{array}{l}1 \\
2 \\
3\end{array}$ \\
\hline & Never & 6 & Total & & 75 \\
\hline
\end{tabular}

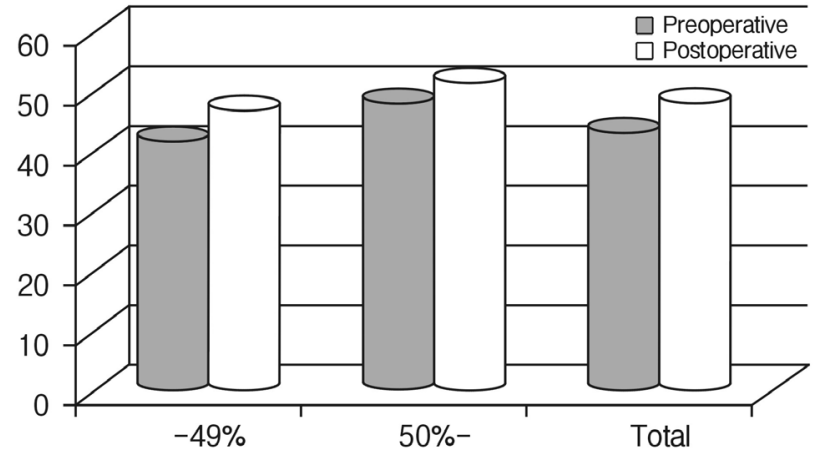

Fig. 2. Degree of lumbar lordotic angle.

In spite of no statistical significance, mean lordosis was changed to $48.2 \pm 10.3^{\circ}$ at last follow-up ( $\mathrm{p}>0.05$ ) (Fig. 2).

\section{Degree of Focal Segmental Angle}

Degree of focal segmental angle, measured from the upper endplate of slipped vertebra to lower endplate of adjacent vertebra, was $10.1 \pm 8.5^{\circ}$ before surgery. At the latest follow-up, the focal segmental angle was $15.9 \pm 6.0^{\circ}$, which improved sig-

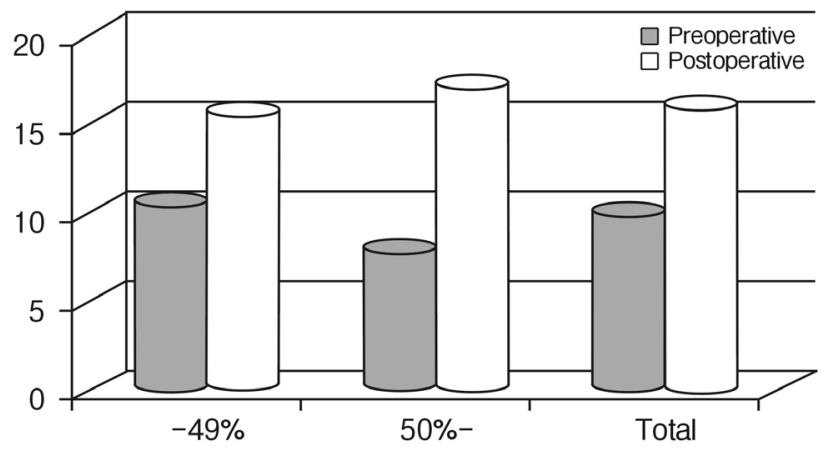

Fig. 3. Degree of focal segmental angle.

nificantly $(\mathrm{p}<0.01)$ (Fig. 3).

\section{Clinical Outcome}

There was no case required a blood transfusion. The mean LBOS prior to surgery was 32.5 , which improved to 53.1 at the last follow-up $(p=0.037)$. From a preoperative average of 7.5, the VAS score was decreased significantly to 3.0 at 7 days postoperatively and 2.9 at the final follow-up $(p=0.015)$. 

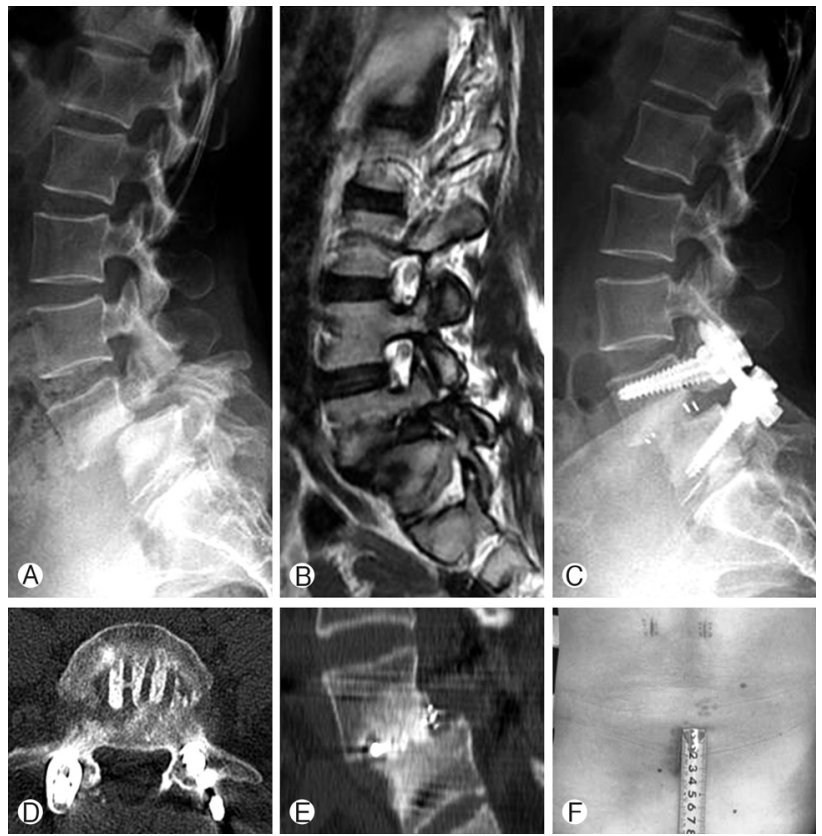

Fig. 4. A 47-year-old man with Grade III spondylolisthesis at L45 level. (A, B) Simple lateral radiograph and magnetic resonance image show Grade III spondylolisthesis. (C, D, E) Postoperative simple lateral radiograph and computed scans taken 23 months later reveal solid bone fusion with significant reduction. (F) Miniopen PLIF was possible by just $3.5 \mathrm{~cm}$ of midline skin incision.
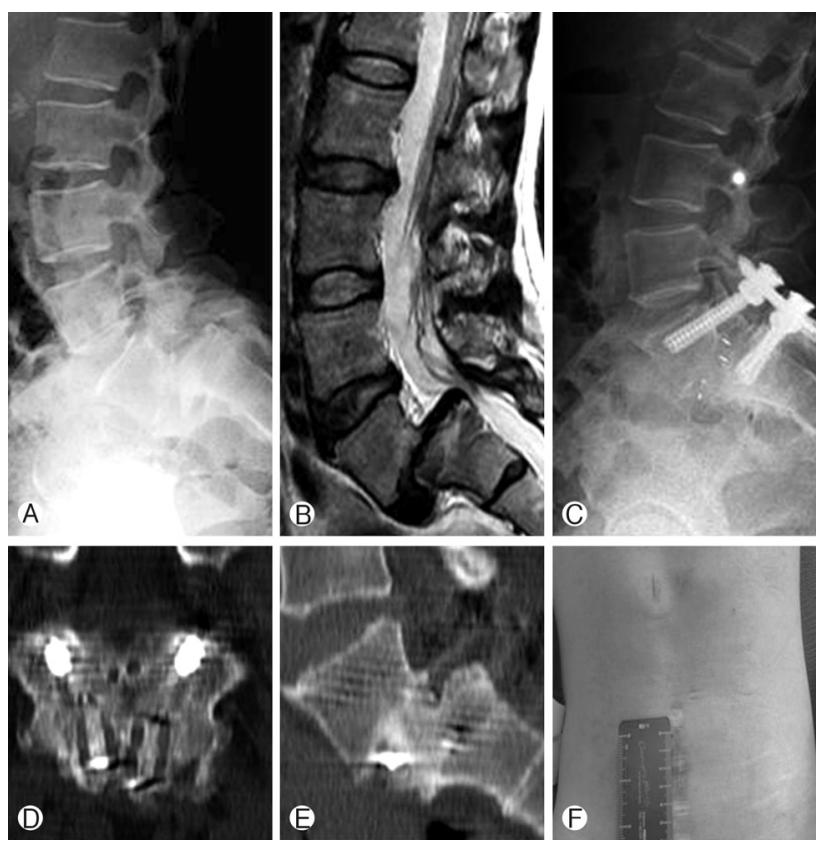

Fig. 5. A 52-year-old man with Grade IV spondylolisthesis at L5-S1 level. (A, B) Simple lateral radiograph and magnetic resonance image show Grade IV spondylolisthesis. (C, D, E) Postoperative simple lateral radiograph and computed scans taken 14 months later reveal solid bone fusion with significant reduction. (F) Mini-open PLIF was possible by just $4 \mathrm{~cm}$ of midline skin incision.

\section{Complications}

There was no case to be converted into conventional open surgery due to technical difficulty. Complications included one case of medial penetration of pedicle border, which needed screw re-insertion and two cases with a superficial wound infection. However, there was no pseudoarthrosis. All patients had a solid bony fusion at the last follow-up, without any dislocation compared to the immediate postoperative radiographs. Two patients with Grade III spondylolisthesis showed a signs of a transient root lesion after surgery ( 1 case of transient and mild motor weakness and 1 case of radiating pain and sensory change), which resolved completely. However, there were no permanent neurological sequelae as a result of miniopen PLIF (Fig. 4 and 5).

\section{DISCUSSION}

Spondylolisthesis is a relatively common disease with an incidence approximately $5 \%$ of the population requiring fusion surgery ${ }^{4}$. Low-grade spondylolisthesis may be managed by conservative treatment in some cases, but in moderate to high grade spondylolisthesis, nonoperative methods are not able to prevent the progressive back and radiating pain, increasing slip and deformity or cauda equina symptoms. Decompression was introduced as the treatment for spondylolisthesis that induces radiating pain by Gill in 1955, and subsequently various surgical techniques have been performed ${ }^{1}$. Symptomatic spondylolisthesis usually require surgical intervention, the goals of which include the stabilization of the motion segment, decompression of neural elements, reconstitution of disc space height, and restoration of sagittal plane translational and rotational alignment. Among them, PLIF is a widely performed procedure and it has been associated with the improvement of the fusion rate while restoring disc height and maintaining vertebral alignment for spondylolisthesis. Moreover, recently, miniopen PLIF using percutaneous screw fixation system can provide many potential benefits compared to conventional PLIF ${ }^{5)}$. For the treatment of symptomatic spondylolisthesis, however, the role of compulsory translational reduction and instrumentation is controversial. Some proponents state that the reduction itself will improve the rate of fusion and improve spinopelvic balance ${ }^{3)}$. The theoretical advantages of slip reduction include improved spine biomechanics, better nerve root decompression, and chance to obtain fusion because it provides an increased surface area of the fusion bed and the fusion is no longer under the influence of tension and anterior shear forces. Another advantage of slip reduction is the correction of the sagittal deformity to improve posture. Re-aligning the spine and achieving sagittal balance are important in the long run 
by preventing premature adjacent level disc degeneration ${ }^{12}$. On the contrary, a forceful and mandatory instrumented slip reduction can certainly lead to reduction even by $100 \%$, which will increase the risk of permanent complications. The major disadvantage of complete slip reduction is the increased risk of neural injury caused by excessive distraction of nerve roots ${ }^{11)}$. The various hypothetical cause of neurologic injury include direct pressure on the nerve root during reduction, impingement of the nerve roots on the iliolumbar ligaments, extradural tension on the nerve roots, and disc ma- terial extruded into the canal ${ }^{6,8)}$. Moreover, for the treatment of high-grade spondylolisthesis, the risk of neural injury caused by forceful reduction and pseudarthrosis is much higher ${ }^{9,10}$. To overcome these disadvantages, spontaneous partial reduction techniques have evolved. Pan et al. ${ }^{12)}$ reported that circumferential release, including scar resection for posterior release complete disc removal and distraction with rupture of annulus conjunct with anterior longitudinal ligament for anterior release in the treatment of low-grade isthmic spondylolisthesis. Significant slip reduction for the group was achieved and the fusion rate approached $100 \%$ with no definite neurological complications. They insisted that spondylolisthesis has a certain trend toward spontaneous reduction intraoperatively, including the reduction of translational and rotational deformity, which can provide good outcomes. The technique described here also meets these requirements. Reduction of the slippage was achieved by a combination of two principles. First, circumferential release was applied. Resection of the scar around the pars interarticularis would lead to liberation of the nerve roots, which could help to achieve posterior release. The disc was totally resected with removing the anterior annulus as much as possible even in conjunction with ALL, and the disc space was gradually distracted with sequential disc shavers to fully restore the disc space height, accomplishing anterior release. Second, with the insertion of cages to maintain the height, the following influence of percutaneous pedicle fixation on the spinal alignment by compressive force, additional reduction could be achieved without any application of powerful posterior translational force. As a result, no forceful tension acts on the pedicle screw system, obviously decreasing the anterior shear forces. All the surgical procedures in this study were performed by a single surgeon to eliminate the variable effects of different surgeon on surgical outcome. However, larger-scale, multicenter studies involving more surgeons are necessary to validate our results.

\section{CONCLUSION}

Mini-open PLIF following circumferential release contributes to achieving spontaneous slip reduction without neuro- logic deterioration. This minimal invasive technique is safe and efficient even in the moderate to high grade spondylolisthesis.

\section{REFERENCES}

1. Gill GG, Manning JG, White HL: Surgical treatment of spondylolisthesis without spine fusion; excision of the loose lamina with decompression of the nerve roots. J Bone Joint Surg Am 37:493-520, 1955

2. Harris IE, Weinstein SL: Long term follow-up of patients with grade-III and IV spondylolisthesis. Treatment with and without posterior fusion. J Bone Joint Surg Am 69:960-969, 1987

3. Kawakami M, Tamaki T, Ando M, Yamada H, Hashizume H, Yoshida M: Lumbar sagittal balance influences the clinical outcome after decompression and posterolateral spinal fusion for degenerative lumbar spondylolisthesis. Spine (Phila Pa 1976) 27: 59-64, 2002

4. Kim HS, Park IH, Ryu JK, Kim SW, Shin H: Bone cement augmentation of pedicular screwing in severe osteoporotic spondylolisthetic patients. J Korean Neurosurg Soc 42:6-10, 2007

5. Kim HS, Park KH, Ju CI, Kim SW, Lee SM, Shin H: Minimally invasive multi-level posterior lumbar interbody fusion using a percutaneous inserted spinal fixation system: technical tips, surgical outcomes. J Korean Neurosurg Soc 50:441-445, 2011

6. Kleihues H, Albrecht S, Noack W: Topographic relations between the neural and ligamentous structures of the lumbosacral junction: in vitro investigation. Eur spine J 10:123-132, 2001

7. Lee DY, Lee SH, Maeng DH, Jang JS: Anterior lumbar interbody fusion with pedicle screw fixation for elderly isthmic spondylolisthesis. J Korean Neurosurg Soc 40:175-179, 2006

8. Maurice HD, Morley TR: Cauda equina lesions following fusion in situ and decompressive laminectomy for severe spondylolisthesis. Four case reports. Spine (Phila Pa 1976) 14:214-216, 1989

9. Molinari RW, Bridwell KH, Lenke LG, Baldus C: Anterior column support in surgery for high-grade, isthmic spondylolisthesis. Clinical Orthop Relat Res 394:109-120, 2002

10. Molinari RW, Bridwell KH, Lenke LG, Ungacta FF, Riew K: Complications in the surgical treatment of pediatric high-grade, isthmic dysplastic spondylolisthesis: A comparison of three surgical approaches. Spine (Phila Pa 1976) 24:1701-1711, 1999

11. Ogilvie JW: Complications in spondylolisthesis surgery. Spine (Phila Pa 1976) 30:97-101, 2005

12. Pan J, Li L, Qian L, Zhou W, Tan J, Zon L, et al: Spontaneous slip reduction of low-grade isthmic spondylolisthesis following circumferential release via bilateral minimally invasive transforaminal lumbar interbody fusion: technical note and short-term outcome. Spine (Phila Pa 1976) 36:283-289, 2011

13. Petraco MD, Spivak JM, Cappadona JG, Frederick J, Neuwirth MG: An anatomic evaluation of L5 nerve stretch in spondylolisthesis reduction. Spine (Phila Pa 1976) 21:1133-1138, 1996

14. Smith MD, Bohlmann HH: Spondylolisthesis treated by a singlestage operation combining decompression with in situ posterolateral and anterior fusion: an analysis of eleven patients who had long-term follow-up. J Bone Joint Surg Am 72:415-421, 1990

15. Yoon WS, Cho KS, Park JH, Park CK, Yoo DS, Huh PW, et al: Comparison of clinical outcomes: Posterolateral fusion versus posterior lumbar interbody fusion in low-grade degenerative spondylolisthesis. Korean J Spine 1:481-488, 2004 